\title{
Characterization of bacterial cellulose produced via fermentation of acetobacter xylinum 0416
}

\author{
Khairul Azly Zahan ${ }^{1, *}$, Afiq Haiqal Iman Anuar ${ }^{1}$, Norhayati Pa'e ${ }^{2}$, Leong Chean Ring ${ }^{1}$, Tong Woei Yenn ${ }^{1}$, \\ Mahfuzah Mustapha ${ }^{1}$ \\ ${ }^{1}$ Malaysian Institute of Chemical and Bioengineering Technology, Universiti Kuala Lumpur, Vendor City Taboh Naning, 78000 \\ Alor Gajah, Melaka, Malaysia \\ ${ }^{2}$ Faculty of Chemical and Energy Engineering, Universiti Teknologi Malaysia, 81310 Skudai, Johor, Malaysia
}

\section{ARTICLE INF O}

\section{Article history:}

Received 3 November 2016

Received in revised form

18 January 2017

Accepted 18 January 2017

\section{Keywords:}

Bacterial cellulose

FTIR

FESEM

TGA

Physiochemical properties

\begin{abstract}
A B S T R A C T
The production of plant-based cellulose products had contributed to the increasing rate of deforestation activities. Bacterial cellulose (BC) produced via fermentation process can be considered as an alternative. In this study, BC was produced by fermentation of Acetobacter xylinum 0416 and further analyzed to determine its physiochemical properties. The characterization of the BC was carried out through fourier transform infrared spectroscopy (FTIR), field emission scanning electron microscope (FESEM), thermogravimetric analysis (TGA), $\mathrm{pH}$, moisture content, compressibility index and swelling properties. Then, it was compared with plant-based cellulose products which are carboxymethyl cellulose (CMC) and cellulose powder (CP). FTIR analysis demonstrated the similar properties between BC, CMC and CP while FESEM depicted a smoother surface and nanostructure of the BC. The TGA analysis indicated that $\mathrm{BC}$ has the highest thermal stability compared to $\mathrm{CMC}$ and $\mathrm{CP}$. The other characterization results showed that $\mathrm{BC}$ displayed promising properties compared to CMC and CP. These findings further support the potential of substituting the use of plant-based cellulose products in the market with BC produced by A.xylinum 0416 .
\end{abstract}

(C) 2017 The Authors. Published by IASE. This is an open access article under the CC BY-NC-ND license (http://creativecommons.org/licenses/by-nc-nd/4.0/).

\section{Introduction}

In recent years, plant-based cellulose was widely used in the industries for the production of various products. However, the use of cellulose crops from wood and cotton give direct impact on the earth's carbon cycle as it used up forest resources. Additionally, the manipulation of trees for these purposes has continuously depleted forest resources lead to highly needed for other alternative. The use of alternative non-wood sources of fiber in preparation of pulp for industrial applications has received substantial attention. The main reason for the continuous attention increase in this area is a decrease in wood availability with the increasing demand for market pulp in some rapidly developing countries in Asia, Africa and Latin America (Ohwoavworhua et al., 2009). Therefore, bacterial

\footnotetext{
* Corresponding Author.

Email Address: khairulazly@unikl.edu.my (K. A. Zahan) https://doi.org/10.21833/ijaas.2017.03.004

2313-626X/C 2017 The Authors. Published by IASE.

This is an open access article under the CC BY-NC-ND license

(http://creativecommons.org/licenses/by-nc-nd/4.0/)
}

cellulose (BC) can be used as an alternative for plantbased cellulose products.

$\mathrm{BC}$ is an exopolysaccharide produced by various species of bacteria (Jonas and Farah, 1998). BC possesses special and unique properties that differ from plant-based cellulose. It is chemically pure and free of lignin and hemicelluloses. When compared to plant-based cellulose, BC has a higher crystallinity, degree of polymerization, tensile strength, moldability, biocompatibility and transparency. Furthermore, the ultra-high strength and toughness of BC make it an ideal raw material for high performance applications such as composites, pharmaceuticals, textiles, mining, and refinery. In food applications, BC can be used in diverse ways such as low-calorie additive, thickener, stabilizer and texture modifier (Chawla et al., 2009).

Other researchers also reported the use of $\mathrm{BC}$ as carrier support for probiotic (Jagannath et al., 2010) and for enzyme immobilization (Wu and Lia, 2008). In practice, the industrialist might take advantage towards the use of $\mathrm{BC}$ in the cases where the chemical purity, mechanical strength, degree of crystallinity or adsorptive capacity in particularly important for their end products. Therefore, it is necessary to determine the physiochemical 
properties of $\mathrm{BC}$ to ensure the feasibility of $\mathrm{BC}$ to be use in the industries.

Hence, in this study, the physiochemical properties of BC produced by Acetobacter xylinum 0416 were investigated. The physiochemical analysis is a method used to determine the characteristic, physical and chemical properties of a material. This includes Fourier transform infrared (FTIR) analysis, field emission scanning electron microscopy (FESEM), thermal stability using thermogravimetric analysis (TGA), $\mathrm{pH}$, moisture content, compressibility index and swelling index. Additionally, the properties of BC also had been compared with the plant-based cellulose products; carboxymethyl cellulose (CMC) and cellulose powder (CP).

\section{Material and methods}

\subsection{Fermentation process}

The fermentation medium was prepared in $3 \mathrm{~L}$ distilled water containing $60 \mathrm{~g}$ glucose, $8 \mathrm{~g}$ sodium hydrogen phosphate $\left(\mathrm{Na}_{2} \mathrm{HPO}_{4}\right), 15 \mathrm{~g}$ bactopeptone, $15 \mathrm{~g}$ yeast extract and $3.45 \mathrm{~g}$ citric acid. The fermentation medium was sterilized using an autoclave at $121^{\circ} \mathrm{C}$ for $15 \mathrm{~min}$. The fermentation medium was poured into ten separated containers which each container was filled with $300 \mathrm{ml}$ of fermentation medium. Then $10 \%(\mathrm{v} / \mathrm{v})$ of the strain A.xylinum 0416 was transferred into each of the containers. The fermentation medium was incubated for 14 days at $28 \pm 1^{\circ} \mathrm{C}$ as the medium went through a static fermentation to obtain the BC pellicles (Zahan et al., 2015).

\subsection{Preparation of $B C$ powder}

The BC pellicle obtained was washed thoroughly with water. Then it was soaked and treated with boiling water at $100^{\circ} \mathrm{C}$ for $1 \mathrm{~h}$ using a water bath. Then the BC pellicle was ground using a heavy duty blender and poured into a tray. It was dried in the oven at $50^{\circ} \mathrm{C}$ for $24 \mathrm{~h}$. The dried $\mathrm{BC}$ was then ground again until a fine BC powder was obtained (Halib et al., 2012).

\subsection{Fourier transforms infrared (FTIR) analysis}

The $\mathrm{BC}, \mathrm{CMC}$ and $\mathrm{CP}$ samples were mixed with potassium bromide (1:100), pulverized with a mortar and pestle and compressed into tablets separately. The FTIR analysis was carried out using FTIR spectrometer with the resolution of $4 \mathrm{~cm}^{-1}$ in the range of 4000 to $400 \mathrm{~cm}^{-1}$ (Shaharuddin and Muhamad, 2015).

\subsection{Field emission scanning electron microscope (FESEM)}

The BC, CMC and CP samples were analyzed using the FESEM at $28 \pm 1^{\circ} \mathrm{C}$ with an accelerating voltage at
$10 \mathrm{kV}$. All samples were mounted and observed on the aluminum stub with carbon tape. An imaging magnification of approximately 15000, 10000, 5000 and 2500 times were used. The micrograph of all samples was collected and recorded (Alyamani and Lemine, 2012).

\subsection{Thermogravimetric analysis (TGA)}

Ten milligrams (10 mg) of $\mathrm{BC}, \mathrm{CMC}$ and $\mathrm{CP}$ samples were prepared and placed in a sample pan separately. The analysis was performed at $10^{\circ} \mathrm{C} / \mathrm{min}$ from 30 to $950^{\circ} \mathrm{C}$ for $65 \mathrm{~min}$. The differential thermogravimetric (DTG) curve of all samples was derived using Pyris 1 software provided by Perkin Elmer (Selvakumaran and Muhamad, 2015).

\subsection{Swelling properties}

Two grams (2 g) of BC, CMC and CP samples were mixed with $40 \mathrm{~g}$ of different solution separately (distilled water, acetone, dimethyl sulfoxide (DMSO) and acetic acid). The suspension was allowed to stand for $2 \mathrm{~h}$. The suspensions were centrifuged at $3500 \mathrm{rpm}$ for $30 \mathrm{~min}$. The supernatant was removed and the wet precipitate was weighed. The steps were repeated three times to get the average reading (Goh et al., 2012). The result was expressed as a gram of water per gram of sample (w/w) by using Eq. 1 .

liquid retention level $=\frac{\mathrm{M}_{1}}{\mathrm{M}_{2}}-1 \times 100$

where, $M_{1}=$ weight of wet sample and $M_{2}=$ weight of dry sample.

\subsection{Compressibility index}

Five grams ( $5 \mathrm{~g}$ ) of $\mathrm{BC}, \mathrm{CMC}$ and $\mathrm{CP}$ samples were accurately weighed and poured into a $100 \mathrm{ml}$ graduated cylinder separately. Then, the bulk volume was taken (the initial reading). After that, the cylinder was tapped at height of $2.5 \mathrm{~cm}$ on the hard surface until a constant volume was obtained. The tap volume was taken as a final reading. The procedure was repeated three times to get the average value (Azubuike and Okhamafe, 2012). The bulk density, D bulk and tapped density, $\mathrm{D}_{\text {tap }}$ were calculated using Eqs. 2 and 3.

$D_{\text {bulk }}=\frac{w}{V_{0}}$
$D_{\text {tap }}=\frac{w^{\prime}}{V_{1}}$

where, $\mathrm{V}_{\mathrm{o}}=$ volume of the bulk, $\mathrm{V}_{1}=$ the volume tap density and $W=$ weight of the celluloses (5g).

The Carr's index was calculated using Eq. 4 and the Hausner ratio was calculated using Eq. 5.

Carr's index $=\frac{\mathrm{D}_{\text {tap }}-\mathrm{D}_{\text {bulk }}}{\mathrm{D}_{\text {tap }}} \times 100$

Hausner ratio $=\frac{D_{\text {tap }}}{D_{\text {bulk }}}$ 


\subsection{Determination of $\mathrm{pH}$}

One gram ( $1 \mathrm{~g}$ ) of $\mathrm{BC}, \mathrm{CMC}$ and $\mathrm{CP}$ samples were mixed with $40 \mathrm{ml}$ of distilled water at $\mathrm{pH} 6.8$ separately. The solution was stirred for 15 min using a hot plate and magnetic stirrer. The $\mathrm{pH}$ was checked using the $\mathrm{pH}$ meter and the reading was recorded. The steps were repeated three times and the average reading was calculated (Halib et al., 2012).

\subsection{Determination of moisture content}

Five grams (5 g) of BC, CMC and CP samples were accurately weighted separately. Then, the samples were placed in the moisture analyzer and the reading was recorded. The steps were repeated three times and the average reading was calculated (Azubuike and Okhamafe, 2012).

\section{Results and discussion}

\subsection{Fourier transforms infrared (FTIR) analysis}

Fig. 1 shows the functional group and chemical bonding of $\mathrm{BC}, \mathrm{CMC}$ and $\mathrm{CP}$ samples. The main peaks depicted for all samples are $-\mathrm{H}$ bond and $-\mathrm{OH}$ group (3200-3500 $\left.\mathrm{cm}^{-1}\right)$, -C-H stretching (2800-2900 $\mathrm{cm}^{-}$ $\left.{ }^{1}\right),-C=0$ stretching $\left(1600-1700 \mathrm{~cm}^{-1}\right)$, the carbonyl groups of the asymmetric $-\mathrm{CH}_{2}$ bending and wagging (1300-1500 $\mathrm{cm}^{-1}$ ) and-C-O-C- stretch of the $\beta-1,4-$ glycosidic linkage $\left(1000-1200 \mathrm{~cm}^{-1}\right)$ which similar to non-microbial source of natural cellulose (Pachuau, 2015; Barbara et al., 2008).

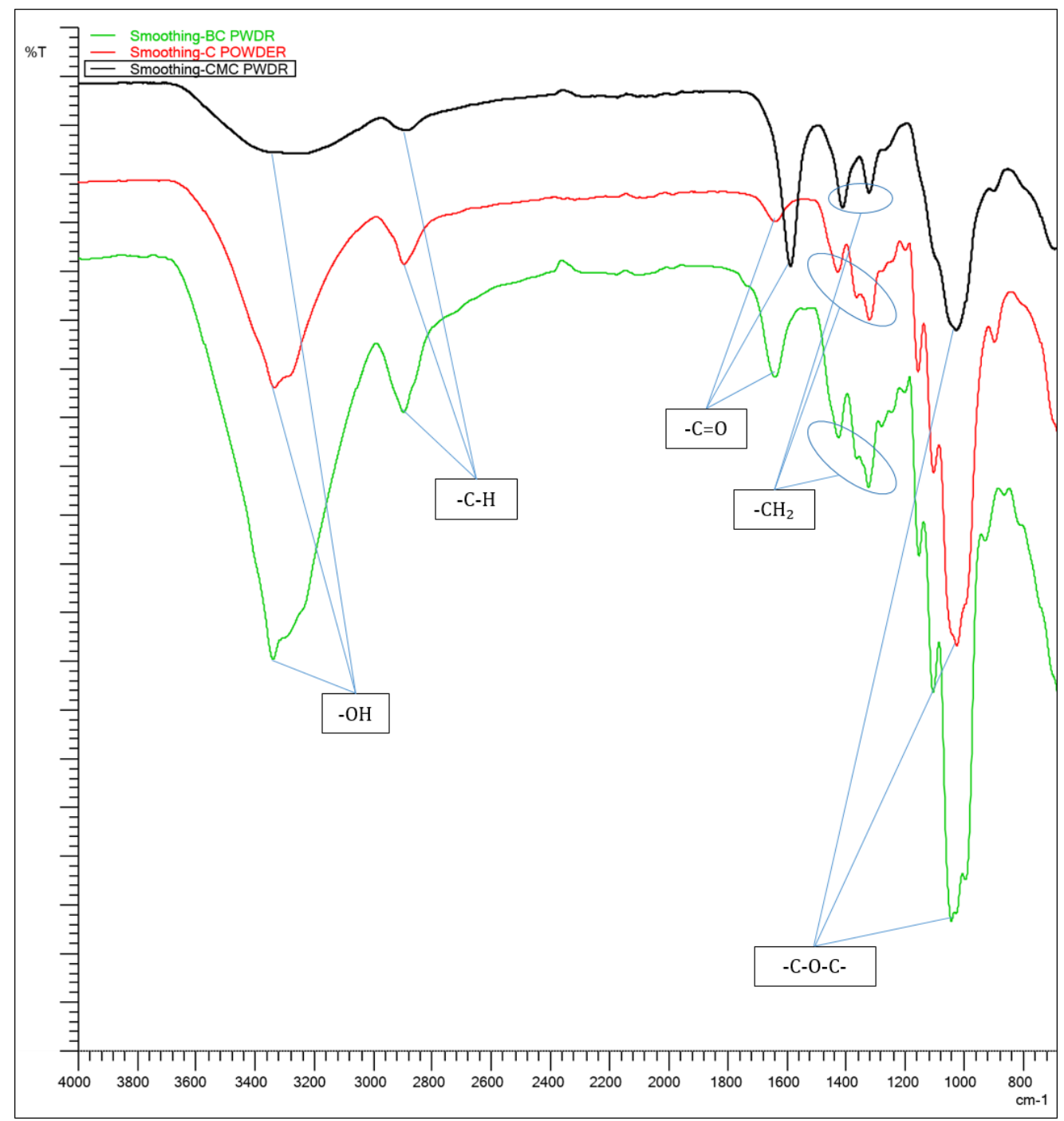

Fig. 1: Fourier Transform Infrared spectroscopy (FTIR) for BC, CMC and CP

As overall, this result particularly proved that BC, CMC and CP have a similar functional groups and chemical bonding. Thus, the chemical nature of $\mathrm{BC}$ was confirmed by the infrared spectra of CMC and $\mathrm{CP}$. These results also had depicted that the $\mathrm{BC}$ produced by A.xylinum 0416 was confirmed as pure cellulose

\subsection{Field emission scanning electron microscope (FESEM)}

The morphological structures of $\mathrm{BC}, \mathrm{CMC}$ and $\mathrm{CP}$ sample was done using FESEM analysis at the magnification of 2500 times as shown in Fig. 2. 
The image obtained shows that $\mathrm{BC}$ poses a very similar structure with the CMC and CP, plant based cellulose powders. Additionally, the fibrils were organized and tightly packed which conferred a morphological feature similar to the plant based cellulose powder. Besides, the surface of the BC was smoother compared to the plant based cellulose powder.

Further analysis of the BC under the magnification of 5000, 10000 and 15000 times had revealed that the $\mathrm{BC}$ poses a nanostructure with an irregular size and shape of fibrous network as shown in Fig. 3. The nanoparticle provide numerous advantages and applications in the industries since more surface area can be utilize thus enhance their overall capability. This include, nanoparticles can be easily manipulated for both passive and active drug targeting, availability of appropriate matrix helps in increasing the efficacy and reducing side effects of the drug, and finally important to control and sustain release of the drug during the transportation as well as the location of the release.

\subsection{Thermogravimetric analysis (TGA)}

Fig. 4 shows the maximum rates of weight loss for $\mathrm{BC}, \mathrm{CMC}$ and $\mathrm{CP}$ at different temperature. The result obtained was in agreement with Halib et al. (2012) and Barbara et al. (2008) who stated that the maximum rate of weight loss was at 330 to $370^{\circ} \mathrm{C}$.

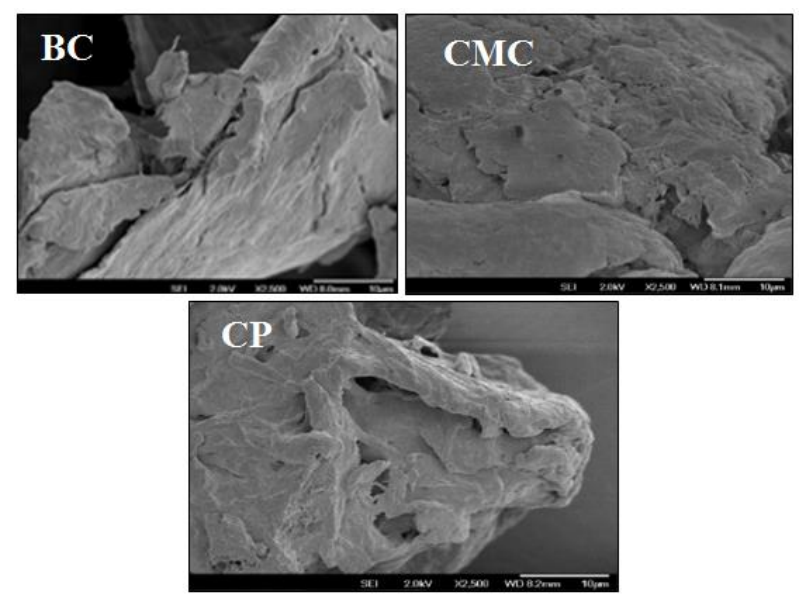

Fig. 2: Micrograph of $\mathrm{BC}, \mathrm{CMC}$ and $\mathrm{CP}$ under the magnification of 2500 times

\subsection{Swelling properties}

Fig. 5 shows the liquid retention level of $\mathrm{BC}$ and CMC in different type of solvent. As overall, BC had shown higher liquid retention level in all solvent compared to CMC which reflect higher swelling properties of BC. The swelling power of the cellulose in the solvent was influenced by the degree of molar volume of the solvent which contribute to the hydrogen bonding capability and the cohesive energy density of the solvent (Goh et al., 2012; Cheng et al., 2010).

The result also depicted that $\mathrm{BC}$ show the highest temperature for the maximum rate weight loss compared to $\mathrm{CMC}$ and $\mathrm{CP}$. On the other hand, the differential thermogravimetric (DTG) curve obtained depicted that the temperature of the maximum weight loss for $\mathrm{BC}$ was shifted almost $63^{\circ} \mathrm{C}$ higher than $\mathrm{CMC}$ and almost $11^{\circ} \mathrm{C}$ higher than $\mathrm{CP}$. This reflects that $\mathrm{BC}$ possessed the highest thermal stability compared to plant cellulose (Cheng et al., 2009). Additionally, the TGA curve of BC showed a typical decomposition curve of pure compound where only one step of decomposition was observed (Bottom, 2008). Thus this result had indicated the purity of BC produced by A.xylinum 0416.
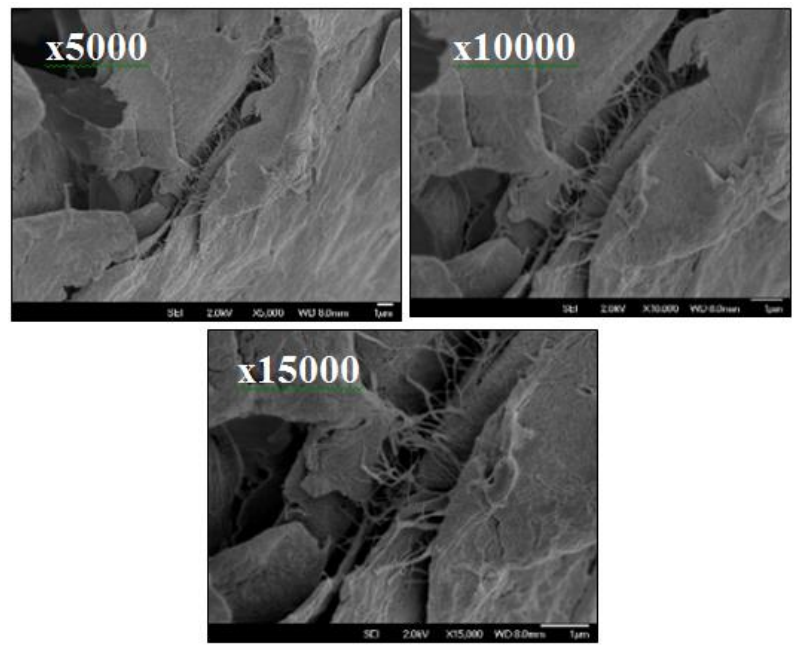

Fig. 3: Micrograph of $B C$ under the magnification of 5000, 10000 and 15000 times

Swelling power also indicates their water holding capacity. The water binding capacity in commercial cellulose-based products is important especially when it is used as a thickener, adhesive, binder, encapsulating agent, film former, gelling agent, texturizer and fat-sparing agent (Kaur et al., 2011).

\subsection{Compressibility index, moisture content and pH}

Table 1 summarized the compressibility index, moisture content and $\mathrm{pH}$ value for $\mathrm{BC}$ and $\mathrm{CMC}$. The compressibility index of $\mathrm{BC}$ and $\mathrm{CMC}$ was determined by Carr's index and Hausner ratio. The Carr's index of BC and CMC powder are $4.90 \%$ and $6.10 \%$ respectively. While the Hausner ratio for $\mathrm{BC}$ and $\mathrm{CMC}$ are 1.05 and 1.06 respectively. According to Goh et al. (2012), the excellent Carr's index range was at the range of 5 to $10 \%$. These results indicate that $\mathrm{BC}$ shows a better flow property compared to CMC. While Azubuike and Okhamafe (2012) stated that the smaller Carr's index exhibits a smaller compressibility index and angle of repose, indicating and confirming its better flow property.

Table 1 also depicted that the moisture content of CMC was slightly higher than BC. According to Goh et al. (2012), the acceptable range of the moisture content for cellulose powder product was in the range of 5 to $7 \%$. Finally, the $\mathrm{pH}$ recorded for both $\mathrm{BC}$ and $\mathrm{CMC}$ was almost the same and nearly to the neutral values. 


\section{Conclusion}

The study was set out to determine the properties of BC produced via fermentation using the A.xylinum 0416. The data collected had proven that $\mathrm{BC}$ shows a better and promising characteristic compared to plant based cellulose products (CMC and $\mathrm{CP}$ ). In conclusion, $\mathrm{BC}$ can be used as one of the alternative to replace the plant based cellulose product in the industries which finally help us to preserve our forest for the benefit of the future generations.

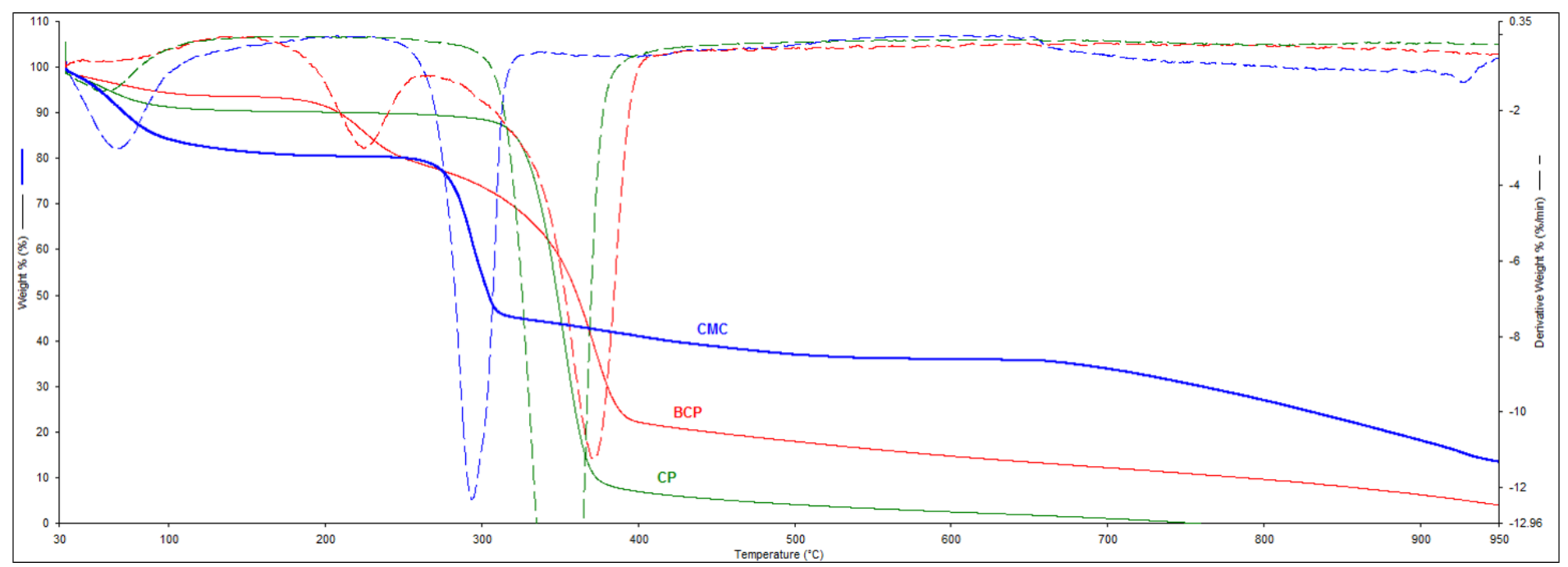

Fig. 4: The TGA and DTG curve of $\mathrm{BC}, \mathrm{CMC}$ and $\mathrm{CP}$

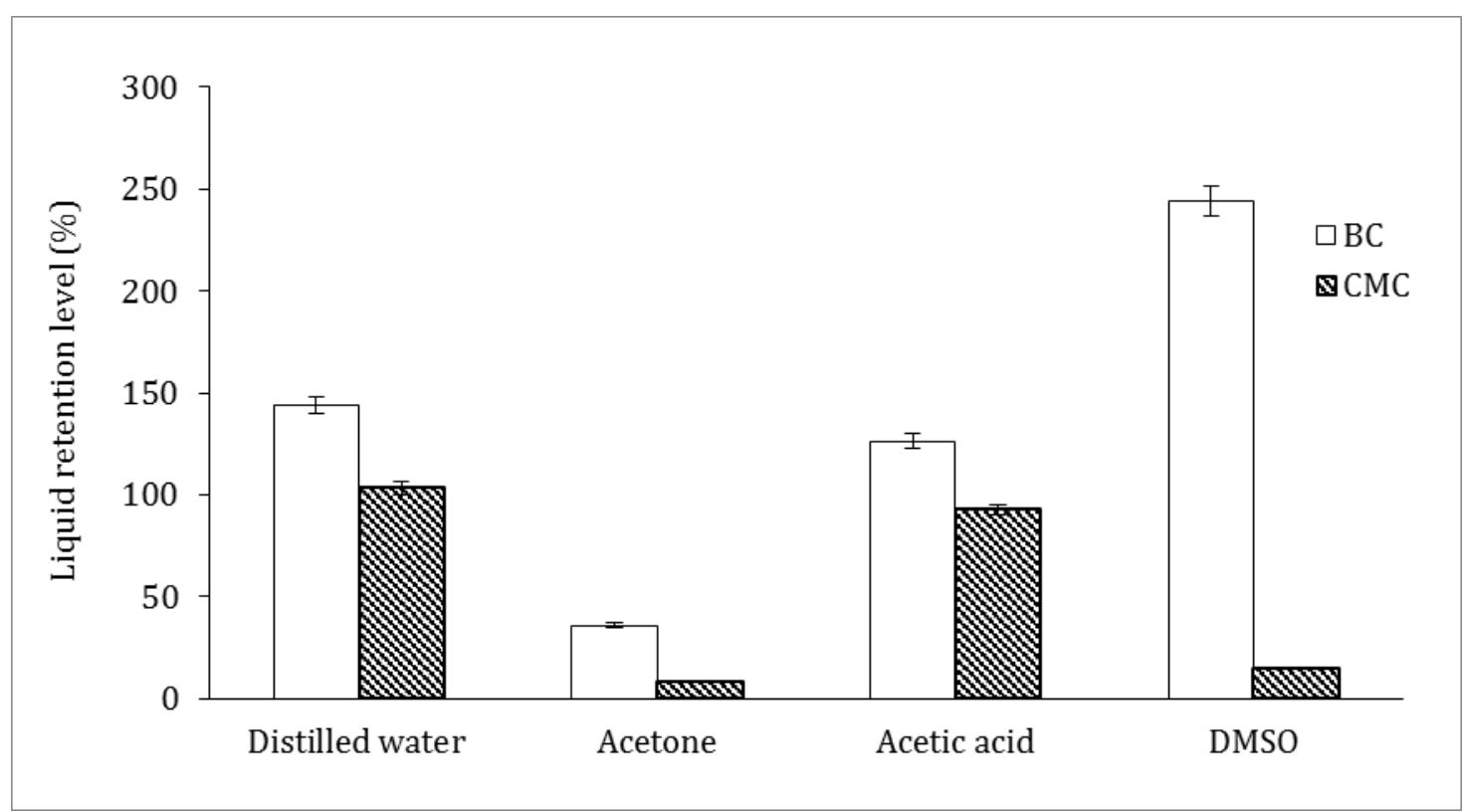

Fig. 5: The liquid retention level of $\mathrm{BC}$ and $\mathrm{CMC}$ in four different solvent

Table 1: The compressibility index, moisture content and $\mathrm{pH}$ of BC and CMC

\begin{tabular}{cccc}
\hline & $\begin{array}{c}\text { Compressibility } \\
\text { Index (\%) }\end{array}$ & $\begin{array}{c}\text { Moisture } \\
\text { Content (\%) }\end{array}$ & $\mathrm{pH}$ \\
\hline $\mathrm{BC}$ & 5.00 & 8.75 & 6.60 \\
$\mathrm{CMC}$ & 6.00 & 11.84 & 7.10 \\
\hline
\end{tabular}

\section{Acknowledgment}

The authors gratefully acknowledge the Section of Bioengineering Technology, Malaysian Institute of Chemical and Bioengineering Technology, Universiti Kuala Lumpur for the facilities to perform this research and the Short Term Research Grant (STRG No. 15043).

\section{References}

Alyamani A and Lemine OM (2012). FE-SEM characterization of some nanomaterial, scanning electron microscopy. In: Viacheslav K (Eds.), Scanning Electron Microscopy, 23: 463472. INTECH Open Access Publisher, Rijeka, Croatia.

Azubuike CP and Okhamafe AO (2012). Physiochemical, spectoscopic and thermal properties of microcrystalline cellulose derived from corn cobs. International Journal of Recycling of Organic Waste in Agriculture, 1(1): 1-7.

Barbara SŚ, Sebastian P, and Dariusz D (2008). Characteristics of bacterial cellulose obtained from Acetobacter xylinum culture for application in papermaking. Fibres and Textiles in Eastern Europe, 4(69): 108-111.

Bottom R (2008). Thermogravimetric analysis. In: Gabbott P (Eds.), Principles and Applications of Thermal Analysis, 3: 87118. Blackwell Publishing, New Jersey, USA. 
Chawla PR, Bajaj IB, Survase SA, and Singhal RS (2009). Microbial cellulose: Fermentative production and applications. Food Technology and Biotechnology, 47(2): 107-124.

Cheng KC, Catchmark JM, and Demirci A (2009). Enhanced production of bacterial cellulose by using a biofilm reactor and its material property analysis. Journal of Biological Engineering, 3(12): 1-10.

Cheng Q, Wang J, McNeel JF, and Jacobson PM (2010). Water retention value measurements of cellulosic materials using a centrifuge technique. BioResources, 5(3): 1945-1954.

Goh WN, Rosma A, Kaur B, Fazilah A, Karim AA, and Rajeev Bhat (2012). Microstructure and physical properties of microbial cellulose produced during fermentation of black tea broth (Kombucha). II. International Food Research Journal, 19(1): 153-158.

Halib N, Amin MC and Ahmad I (2012). Physicochemical properties and characterization of nata de coco from local food industries as a source of cellulose. Sains Malaysiana 41(2): 205-211.

Jagannath A, Raju PS, and Bawa AS (2010). Comparative evaluation of bacterial cellulose (nata) as a cryoprotectant and carrier support during the freeze drying of probiotic lactic acid bacteria. LWT-Food Science and Technology, 43(8): 1197-1203.

Jonas R and Farah LF (1998). Production and application of microbial cellulose. Polymer Degradation and Stability, 59(13): 101-106.
Kaur M, Oberoi DP, Sogi DS, and Gill BS (2011). Physicochemical, morphological and pasting properties of acid treated starches from different botanical sources. Journal of Food Science and Technology, 48(4): 460-465.

Ohwoavworhua FO, Adelakun TA, and Okhamafe AO (2009). Processing pharmaceutical grade microcrystalline cellulose from groundnut husk: Extraction methods and characterization. International Journal of Green Pharmacy, 3(2): 97-104.

Pachuau LS (2015). A mini review on plant-based nanocellulose: Production, sources, modifications and its potential in drug delivery applications. Mini-Reviews in Medicinal Chemistry, 15(7): 543-552.

Selvakumaran S and Muhamad II (2015). Evaluation of kappa carrageenan as potential carrier for floating drug delivery system: Effect of cross linker. International Journal of Pharmaceutics, 496(2): 323-331.

Shaharuddin S and Muhamad II (2015). Microencapsulation of alginate-immobilized bagasse with Lactobacillus rhamnosus NRRL 442: enhancement of survivability and thermotolerance. Carbohydrate Polymers, 119: 173-181.

Wu SC and Lia YK (2008). Application of bacterial cellulose pellets in enzyme immobilization. Journal of Molecular Catalyst B: Enzymatic, 54(3-4): 103-108.

Zahan KA, Nordin K, Mustapha M, Zairi M, and Naqiuddin M (2015). Effect of incubation temperature on growth of Acetobacter xylinum 0416 and bacterial cellulose production. Applied Mechanics and Materials, 815: 3-8. 